\title{
O DIREITO À SAÚDE NO ORDENAMENTO JURÍDICO BRASILEIRO: UMA ANÁLISE HISTÓRICO-LEGISLATIVA-CONCEITUAL DA (DES)CENTRALIZAÇÃO DO SISTEMA DE SAÚDE
}

\author{
THE HEALTH RIGHT AND THE BRAZILIAN LEGAL ORDER: A HISTORICAL- \\ LEGISLATIVE-CONCEPTUAL ANALYSIS OF THE HEALTH SYSTEM (DE) \\ CENTRALIZATION.
}

\section{Edith Barbosa Ramos}

Pós-Doutora em Direito Sanitário pela Fundação Oswaldo Cruz - FIOCRUZ/Brasília/DF. Doutora em Políticas

Públicas pela Universidade Federal do Maranhão. Mestre em Direito pela Universidade Federal de Minas Gerais.

Graduada em Direito pela Universidade Federal do Maranhão. Professora do Departamento de Direito da

Universidade Federal do Maranhão. Professora e Vice-Coordenadora do Mestrado em Direito e Instituições do Sistema de Justiça da Universidade Federal do Maranhão. Coordenadora do Núcleo de Estudos em Direito Sanitário (NEDISA/UFMA). Professora e Pesquisadora da Universidade Ceuma. Professora do IMEC. E-mail: edithramosadv@yahoo.com.br

\section{Fernanda Dayane dos Santos Queiroz}

Mestra em Direito da UFMA. Pós-Graduanda em Direito Público pela Universidade Estácio de Sá/CERS. Advogada. Graduada em Direito pela Universidade Federal do Maranhão (UFMA - 2015). Integrante da Comissão de Bioética e

Biodireito da OAB/MA. Integrou o Núcleo de Estudos em Direito Sanitário - NEDISA e o Núcleo de Estudos em Direito Constitucional - NEDC/UFMA.

E-mail: fernanda.ichs4@yahoo.com.br

\section{Delmo Mattos da Silva}

Realizou doutorado em Filosofia pela Universidade Federal do Rio de Janeiro (2008), mestrado em Filosofia, com Bolsa CAPES, pela Universidade Federal do Rio de Janeiro (2003) e bacharelado em Filosofia pela Universidade

Federal do Rio de Janeiro (2000). Em 2018 concluiu o Estágio de Pós-doutorado em Teoria do Direito, PPGDIR

(UFMA). No âmbito da Pós-Graduação, atua como Professor Colaborador do Programa de Pós-Graduação em

Direito e Instituições do Sistema de Justiça, vinculado a Universidade Federal do Maranhão (UFMA). Atua como

Professor Permanente do Programa de Pós-Graduação em Meio Ambiente - UniCEUMA. É líder do Grupo de Pesquisa Justiça, Poder e Relações Éticas na Contemporaneidade - (UniCEUMA - Cadastrado no Diretório do Grupo de Pesquisa do CNPq/2015). Pesquisador do Grupo de Pesquisa Contratualismo Moral e Político (UFRRJ -

Cadastrado no Diretório do Grupo de Pesquisa do CNPq/2014). Pesquisador com projeto de pesquisa aprovado na FAPEMA (Fundação de Amparo à Pesquisa e ao Desenvolvimento Científico e Tecnológico do Maranhão). Íntegra como membro do Núcleo Estruturante do GT Hobbes, da ANPOF. Na graduação, atua como Professor de Filosofia

Jurídica na UNDB e UNICEUMA.

E-mail: delmomattos@hotmail.com

Recebido em: 11/04/2019

Aprovado em: 14/01/2021

RESUMO: A construção do presente artigo tem como objetivo realizar uma análise da construção do direito à saúde no ordenamento jurídico nacional após a promulgação da Constituição Cidadã, de suas emendas e das leis que instituíram e regulamentaram o Sistema Único de Saúde. Insere-se 
a esse estudo a importância da publicação de Normas Operacionais Básicas do Sistema de Saúde Brasileiro e a modificação sistemática do instituído por via legal e constitucional, a fim de observar a presença da forte centralização administrativa da União, assim como a menor preocupação com a garantia da universalidade do direito à saúde. No que se refere à metodologia empregada, o presente artigo adotou a revisão bibliográfica sistemática. Com esta pesquisa, pretende-se, através dos conceitos adotados pelos teóricos e presentes na normativa nacional discutir sobre o forte caráter centralizador da União e destacar a relação com a garantia do direito universal à saúde no Brasil, o qual perpassa por problemas referente ao dispêndio de recursos para seu custeio.

Palavras-chave: Centralização. Custeio. Direito à Saúde. Ordenamento Jurídico Nacional.

ABSTRACT: The construction of this article, dissertation result, aims to analyze the health right construction in the national legal system after the Citizen Constitution enactment, its amendments and the laws that instituted and regulated the Unified Health System This study includes the importance of the Basic Operational Norms publication of the Brazilian Health System and the systematic modification of the established by legal and constitutional means, in order to observe the presence of the strong administrative centralization of the Union, as well as the lower concern with the guarantee of universality of the right to health. With regard to the methodology used, this article adopted a systematic bibliographic review. With this research, it is intended, through the concepts adopted by the theoreticians and present in the national legislation, to discuss the strong centralizing character of the Union and to highlight the relationship with the guarantee of the universal right to health in Brazil, which runs through problems related to the expenditure resources for their funding.

Keywords: Centralization. Funding. Health right. National Legal Order.

SUMÁRIO: Introdução. $1 \mathrm{O}$ direito à saúde no ordenamento jurídico brasileiro. 1.1 Concepção de direito à saúde para os órgãos internacionais. $2 \mathrm{O}$ direito à saúde no ordenamento jurídico brasileiro. 2.1 Breve resgate histórico do direito à saúde no Brasil: da garantia do direito à saúde tão somente aos contribuintes até a implementação do SUS. 2.2 A edição de normas infraconstitucionais com o fim de regulamentar o SUS: análise das leis $\mathrm{n}^{\circ}$ 8080/90 e 8.142/90 sob o enfoque constitucional. 2.3 A importância da edição das Normas Operacionais Básicas de Saúde e Norma de Assistência à Saúde (NOB's e NOAS). 2.4 O Pacto pela Saúde e o Pacto de Gestão como instrumento necessário para a busca de consolidação do SUS. 2.5 Demais regulamentações para implementação do Sistema Único de Saúde. Considerações finais. Referências.

\section{INTRODUÇÃO}

O direito à saúde, antes de ser normatizado como um direito constitucional social e fundamental, direcionado para todos era privilégio apenas daqueles que desenvolviam atividade laboral e seus dependentes. Foi tão somente após a promulgação da Constituição Federal de 1988 e da lei 8.080/90 que a garantia desse direito passou a ocorrer através das ações e serviços públicos prestados pelo SUS (Sistema Único de Saúde), o qual tem como principais características ser um sistema único, integrado, universal e gratuito.

Entretanto, a consolidação desse sistema envolve uma série de desafios, como: primar pelo fortalecimento das capacidades administrativas e institucionais dos governos locais, regionais e central, além da necessária gestão dos recursos destinados à saúde e repartição das competências do Sistema de Saúde, a qual deve ocorrer com foco na atividade de saúde preventiva.

Embora haja na Constituição Federal algumas competências do Sistema Único de Saúde e ainda um breve relato de como se dá a organização entre os entes federativos com destaque ao 
financiamento desse sistema, foi apenas com a elaboração de leis específicas que foram regulamentados os procedimentos para o adequado funcionamento do SUS.

Desse modo, com o presente artigo pretende-se realizar uma análise do sistema de saúde brasileiro após a promulgação da Constituição de 1988 e da legislação infraconstitucional criada para regulamentar o Sistema Único de Saúde.

Para tanto, estruturou-se o presente artigo da seguinte forma: inicialmente, aborda-se a conceituação do termo saúde e os principais marcos históricos mundiais para a forma de visualizar o termo. Aborda-se, ainda, nesse primeiro momento, o que representa a garantia do direito à saúde para órgãos internacionais e para alguns teóricos e pesquisadores do direito, da saúde e da ciência política. Na sequência, passa-se para o estudo do sistema normativo de saúde no Brasil após a Constituição Federal de 1988, criação de leis e de normas específicas para a regulamentação do SUS, discutindo aspectos de seu caráter centralizador e dificuldades de garantia de recursos a todos os entes para proceder com o seu financiamento.

\section{CONCEITUAÇÃO DE SAÚDE E INSERÇÃO COMO UM DIREITO}

Para se conceituar o termo saúde deve-se ter em vista a conjuntura social, econômica, política e cultural vivenciada. A conceituação depende da época, lugar, classe social, valores individuais, concepções científicas, religiosas, filosóficas.

Saúde, em português, deriva de salude, vocábulo criado no século XIII (1204), e vem do latim salus (salutis), com o significado de salvação, conservação da vida, cura, bem-estar.

Os diversos significados do termo saúde apresentados por Luz (2009) como derivado do latim puderam ser observados ao longo dos séculos. Sobre o tema, insta para este artigo destacar um grande marco para a saúde, o qual ocorreu somente no século XX, em 1948, com a Declaração Universal dos Direitos do Homem em que a saúde passa a ser qualificada como um direito fundamental do homem.

Vê-se, tal como afirma Ramos (2014) que direito à saúde se refere à garantia de todas as condições necessárias para a sua manutenção como direito à água potável, alimentação, meio ambiente equilibrado, dentre outros. De acordo com a mencionada autora:

A temática da saúde é pluridimensional. Direito humano compreendido como instrumental simultaneamente individual e social. A saúde tem sua efetividade imitada por circunstâncias naturais e socioeconômicas, mas, ao mesmo tempo, é elemento capaz de desencadear um processo de modificação de posturas e ações dos indivíduos, da sociedade, dos governos dos Estados nacionais e das organizações internacionais, na melhoria da qualidade de vida das populações (RAMOS, 2014, p. 23).

Assim, a partir de 1948 a saúde passa a ser reconhecida como direito humano objeto da recém criada Organização Mundial de Saúde.

A Organização Mundial de Saúde possui como finalidade alcançar o mais elevado índice de saúde para todos os povos do planeta, combatendo a mortalidade infantil, tratando de temas como saneamento básico, tratamento de doenças, nutrição, vacinas, envelhecimento e ciclo de vida, entre outros (OMS). Tem como objetivo, de acordo com a Constituição da OMS (1948) a aquisição, por todos os povos, do nível de saúde mais elevado que for possível.

A organização mundial da saúde conceitua o termo como "o estado de mais completo bem-estar físico, mental e social e não apenas ausência de enfermidade". Para Scliar "este conceito refletia uma aspiração nascida dos movimentos sociais do pós-guerra: o fim do colonialismo, a ascensão do socialismo" (2007, p. 40).

Loureiro (2008) define saúde como um verdadeiro bem público global. Exemplifica, ao abordar que até meados do século XIX, a questões envolvendo a saúde eram encaradas como 
meramente nacionais, a partir do século XX, a preocupação no combate à enfermidades - doenças infecciosas - levou a um modelo de cooperação internacional.

Em sentido restrito, Briceño -Léon (2000) conceitua saúde como a síntese de uma multiplicidade de processos que acontecem com o corpo, o ambiente que nos rodeia, as relações sociais, a política e a economia internacional. Considera a crença em um completo estado de bemestar algo ingênuo, pois a falta é algo que constitui o ser humano e a sociedade. Ademais, afirma que o conceito trazido pela OMS seria um conceito "ideal", pouco realista, ou mesmo, conforme trata os ideais da política libertária, tal conceito permitiria abusos por parte do Estado, o qual interviria na vida dos cidadãos, sob o pretexto de promover a saúde.

\subsection{Concepção de direito à saúde para os órgãos internacionais}

Considera Ramos (2014) que a concepção de saúde da OMS integra a ideia de proteção da saúde num contexto geral, reconhecendo seu caráter individual e social. Diante disso, é válido enumerar que a saúde implica a existência de condições para o desenvolvimento das pessoas, bem como se torna imprescindível à redução da violência, eliminação da pobreza, redução do desemprego, conservação do meio ambiente, dentre outras condições socioeconômicas.

Restringindo um pouco mais o conceito de saúde, em termos de percepção em âmbito regional, foi criada a Organização Pan-Americana de Saúde (OPAS), a qual é um organismo internacional de saúde pública, direcionado às Américas, fazendo parte dos sistemas de Organização dos Estados Americanos e da Organização das Nações Unidas e que possui como propósitos fundamentais a proteção e a coordenação dos esforços dos países do Ocidente para combater doenças, prolongar a vida, estimular melhoras físicas e mentais dos habitantes.

É importante destacar que a OPAS periodicamente promove reuniões com agentes governamentais, cujo objetivo consiste em rediscutir as ideias e diretrizes para políticas e ações de saúde para a Região das Américas. Em 2017, ocorreu a 29 Conferência Pan-Americana de Saúde da Opas que resultou na elaboração da Agenda de Saúde Sustentável para as Américas 2018-2030 a qual estabelece onze objetivos e 60 metas envolvendo o desenvolvimento da saúde a nível mundial.

Observa-se a clara relação entre saúde e desenvolvimento econômico do Estado, trazida pela presença de fatores socioeconômicos que influenciam decisivamente na efetividade desse direito à saúde.

\section{O DIREITO À SAÚDE NO ORDENAMENTO JURÍDICO BRASILEIRO}

Sarlet (2007) afirma que a Constituição da República tratou a saúde como direito fundamental da pessoa humana, sendo impossível a sua abolição, visto existir a proteção dos direitos fundamentais, considerados cláusulas pétreas e também tendo em vista que quando se trata de saúde, trata-se também do mais importante bem jurídico a ser protegido, que é a própria vida.

\subsection{Breve resgate histórico do direito à saúde no Brasil: Da garantia do direito à saúde tão somente aos contribuintes até a implementação do SUS}

Referente ao setor da saúde, Carvalho (2013), em breve resgate histórico enuncia que na década de 80 existia a parceria entre a previdência e a saúde pública municipal e estadual, o que foi denominado como Ações Integradas de Saúde (AIS). A partir de 1987, as AIS foram aprimoradas e transformadas nos Sistemas Unificados e Descentralizados de Saúde, o que durou até o início da década de 1990, quando foi implantado o SUS. Sobre o período que antecedeu a criação do SUS, se manifesta Carvalho: 
A discussão de uma proposta inovadora e universal com a comunidade e os técnicos resultou naquilo que se denominou Projeto da Reforma Sanitária. Foi emprestada a Tancredo Neves e apropriada como Proposta de Saúde da Nova República. O movimento foi crescendo e culminou com uma grande assembleia em 1986, que foi a VIII Conferência Nacional de Saúde, em Brasília, com cerca de cinco mil pessoas do Brasil inteiro que referendaram a proposta de Reforma Sanitária. Essa presença maciça dos cidadãos usuários foi possível pois as AIS introduziram Conselhos de Saúde, com participação comunitária, em cada município como condição de adesão à proposta (CARVALHO, 2013, p. 22).

Vê-se que antes da criação do SUS houve muita discussão entre a comunidade, os técnicos e profissionais da saúde sobre a possibilidade de criação de uma proposta inovadora e universal. Esse período de amplo debate denominou-se Projeto de Reforma Sanitária.

De acordo com Ressinger (2008), a partir da segunda metade da década de 70, em vários municípios, começaram a surgir experiências de implantação de redes de atenção básica à saúde: profissionais da saúde coletiva ocupavam importantes espaços institucionais abertos por novos prefeitos municipais.

De fundamental importância no movimento da reforma sanitária foi a VIII Conferência Nacional de Saúde, ocorrida em 1986, em que mais de cinco mil representantes da sociedade civil, oriundos dos mais diversos segmentos sociais e políticos, discutiram um novo modelo de saúde para o Brasil (ESCOREL, 1999).

Ressinger (2008) afirma que os três pontos fundamentais do debate da VIII Conferência Nacional da Saúde, eram: a saúde como um direito, a reformulação do sistema de saúde e o financiamento do setor. Dessa forma, a conferência teve como resultado um consenso político que permitiu a elaboração de um projeto de reforma sanitária que trazia um conceito abrangente de saúde ${ }^{1}$, tratava a saúde como direito de cidadania e dever do Estado e instituiu o Sistema Único de Saúde.

No mesmo período em que ocorria a Reforma Sanitária, passava-se também por uma Reforma de Estado. Elias e Dourado (2011) afirmam que em 1990, passava-se por uma Reforma de Estado, nos moldes do Consenso de Washington, cujas primeiras ações se referem ao ajuste fiscal do Estado, o que ocasiona um violento desfinanciamento das políticas sociais, em particular, a da saúde.

A partir de 2000, Elias e Dourado afirmam que se viveu uma nova etapa, com a presença de correções e avanços em temas pouco difundidos no período anterior. Um exemplo, é a explanação das diretrizes do financiamento e da integralidade da assistência curativa/ preventiva. Mudanças no quesito da descentralização, a qual passa a contemplar a esfera estadual e municipal como indispensáveis para a estruturação do SUS.

Narra Almeida (2012) que "apesar das inúmeras dificuldades de implementação do SUS e dos vários problemas não resolvidos, pode-se dizer que o Brasil ainda constitui um modelo diferenciado em relação aos demais países latino-americanos".

O SUS surge portanto como resultado de um intenso processo de mudanças políticas, em meio a uma conjuntura de crise econômica e um contínuo e gradativo processo de democratização.

\subsection{A edição de normas infraconstitucionais com o fim de regulamentar o SUS: Análise das leis $n^{\circ} 8080 / 90$ e 8.142/90 sob o enfoque constitucional}

Além da Constituição Federal de 1988, foram promulgadas leis infraconstitucionais com o objetivo de criar e viabilizar garantia e cumprimento do direito à saúde no Brasil. Podem ser citadas a lei $n^{\circ} 8.080 / 1990$ regulamentada pelo Decreto $n^{\circ}$ 7.508/2011; a lei $n^{\circ}$ 8.142/90; as Normas

\footnotetext{
${ }^{1}$ A saúde como uma situação individual, mas também um fenômeno social.
}

Revista de Direito Brasileira | Florianópolis, SC | v. 28 | n. 11 | p.104-116 | Jan./Abr. 2021 
Operacionais Básicas do Sistema Único de Saúde - NOB/91 e NOB/96; Emenda Constitucional n. o 29 de 2000; Portaria GM/MS n. ${ }^{\circ} 373$ de 2002 que cria a Norma Operacional da Assistência à Saúde - NOAS-SUS 01/2002 substituindo a NOAS-SUS n01/96 e, por fim, trata-se no decorrer do trabalho da Lei Complementar no 141/2012 e da EC n. 95/2016 intitulada como Emenda do Novo Regime Fiscal.

Além da normativa federal, é importante mencionar que a Constituição Federal garantiu aos Estados-membros a competência para legislar, de forma suplementar, sobre a matéria. Por outro lado, os Municípios, como entes mais próximos dos problemas locais, também receberam da Constituição Federal competência para legislar sobre saúde, desde que trate dos assuntos de interesse local (art. 30, I) ou complemente a legislação federal e estadual (art. 30, II), dentre outras atribuições (art. 30, III ao IX).

Tratando precipuamente sobre a normativa constitucional referente ao tema, insta destacar que a Constituição de 1988 elenca as diretrizes e bases do Sistema Único de Saúde. De acordo com o artigo 196, a saúde é direito de todos e dever do Estado, garantido mediante políticas sociais e econômicas que visem à redução do risco de doenças e de outros agravos e ao acesso universal e igualitário às ações e serviços para sua promoção, proteção e recuperação.

Dispõe ainda o texto constitucional, que as ações e serviços de saúde integram uma rede regionalizada e hierarquizada e constituem um sistema único, organizado de acordo com diretrizes. Mesmo depois da Constituição de 1988 que instituiu o SUS, os serviços de saúde no país ainda possuem características que dificultam a sua implantação, tal como fora pensado. Entre essas características, Cohn (2001) enumerou as seguintes: o fato de ser altamente centralizado, acentuadamente privatizado, crescentemente distante das reais necessidades de saúde da população brasileira, com clara divisão de trabalho entre os setores público e privado, discriminatório e injusto e com acentuadas distorções na sua forma de financiamento.

Outras características bastante problemáticas se referem a não utilização dos recursos para atender as reais necessidades de saúde da população brasileira e a divisão do trabalho entre os setores público e privado.

No que se refere às principais normativas do SUS, faz-se importante destacar, primeiramente, a lei $n^{\circ} 8.080 / 1990$ e a lei $n^{\circ} 8.142 / 1990$. A lei $n^{\circ} 8.080 / 90$ é responsável por regulamentar objetivos, atribuições, princípios, diretrizes, organização, direção e gestão, competências e atribuições, serviços privados de assistência à saúde, recursos humanos e financiamento (dos recursos, da gestão financeira, do planejamento e do orçamento).

A lei 8.080/90 ou, como também é conhecida, a Lei orgânica da Saúde trata sobre vigilância sanitária, epidemiológica, a saúde do trabalhador, a saúde terapêutica, incluindo a assistência farmacêutica, a vigilância nutricional e orientação alimentar, assim como o controle e fiscalização dos alimentos, água, bebidas, substâncias psicoativas, tóxicas, radioativas, a política de sangue, entre outros elementos dispostos no artigo $6^{\circ}$ da Lei da Saúde.

A lei supracitada, dispõe no seu artigo 31 e ss. sobre o financiamento da saúde, que utiliza recursos do orçamento da seguridade social, que são depositados em conta especial, em cada esfera de atuação, de acordo com as metas e prioridades dispostas na Lei de Diretrizes Orçamentárias LDO e essas contas têm os Conselhos de Saúde como órgãos responsáveis pela sua fiscalização.

O Decreto $n^{\circ} 7.508 / 2011$ trata sobre a organização do SUS, que deve ocorrer de forma regionalizada e hierarquizada. Para essa organização, pensou-se nas Regiões de Saúde, visando a construção de uma rede de saúde mais ampla, completa, organizada, especialmente, nos municípios mais afastados da capital, que muitas vezes necessitam se deslocar até à capital para ter seu direito à saúde resguardado.

A segunda normativa infraconstitucional mais importante é a Lei n ${ }^{\circ} 8142 / 90$ que trata, conforme enumera Guerra (2015), de dois assuntos vetados na Lei $n^{\circ}$ 8.080/90, quais sejam: a participação da comunidade, com a criação das Conferências e dos 
Conselhos de Saúde e o financiamento, incluindo transferência intergovernamental de recursos financeiros.

\subsection{A importância da edição das Normas Operacionais Básicas de Saúde e Norma de Assistência à Saúde (NOB's e NOAS)}

Tão importante quanto as leis supracitadas na década de 90 , foi a ocorrência da edição de Normas Operacionais, que, conforme explica Guerra (2015) são instrumentos regulatórios que tem o objetivo de organizar o processo de descentralização e ditar os procedimentos e regras para a implementação do SUS. Cada norma foi um instrumento transitório de regulamentação, substituído à medida que o processo de descentralização da saúde atinge estágios mais complexos.

As NOB's tratam ainda de aspectos de divisão de responsabilidades, relações entre gestores, grandes transformações do sistema de pagamento e critérios de transferência de recursos federais para estados e municípios. Tanaka; et. al. (2017) afirmam, que foi somente após a instituição das Normas Operacionais Básicas que grande parte dos municípios brasileiros vêm assumindo a responsabilidade pela estruturação e gestão de seus sistemas municipais de saúde.

A NOB 91 individualizava o repasse de recursos, com base nos procedimentos e ações de saúde, mas sem uma visão da necessidade de recursos globais. Privilegiava-se alguns procedimentos, como os de maior complexidade.

Nesse início da década de 90, os estados e municípios operam como meros prestadores de serviços, sem autonomia em relação ao planejamento e regulação do sistema de saúde. Isso se deve, de acordo com Tanaka; et. Al (2017). ao fato de que essa NOB tenha sido editada sob a chancela do INAMPS, o mantenedor de um modelo de saúde médico-assistencial-hospitalar. Por outro lado, conclui Tanaka; et. Al que:

A NOB/91 teve seu papel histórico no processo de construção do SUS e destacouse como o primeiro instrumento a regulamentar os inúmeros "espaços abertos" deixados pelas Leis Orgânicas da Saúde. Sua grande limitação é derivada de sua orientação pelos princípios do INAMPS e de seu enfoque dirigido fundamentalmente ao financiamento, com valorização das atividades hospitalares e ambulatoriais, perpetuando a lógica de privilegiamento da assistência médica (e da concepção de saúde tendo a doença como referência), que sempre orientou o INAMPS. (TANAKA; ET. AL, 2017, p. 33).

A NOB 93, diferente da 91, é originária do trabalho do Grupo Especial de Descentralização. Destaca os pressupostos de descentralização, reorganização institucional, reformulação de práticas das três esferas de governo com a existência de relação entre eles e o controle social, propondo o diálogo, a negociação, pactuação promovido a partir da Comissão Intergestores Tripartite $(\mathrm{CIT})^{2}$. A NOB 93 orientou a criação da Comissão Intergestores Bipartite (CIB) em cada Estado, com representação do Estado e do conjunto de municípios.

A estratégia de descentralização da NOB 93 incorporava os estados, e principalmente os municípios como entes federados responsáveis pela condução da política de saúde em seu território, com o objetivo de fazer uma transição entre um modelo de gestão da política próximo ao padrão de Estado unitário, para outro típico de federações.

Guerra (2015) enuncia que o texto da NOB 93 demonstrava preocupação com um processo de descentralização mais voltado à municipalização e de se evitar instâncias regionais intermediárias autônomas, com relacionamento direto das esferas estadual e federal.

\footnotetext{
${ }^{2}$ Com a CIT, a representação de estados e municípios deu-se por suas entidades corporativas oficiais, entre elas, para os municípios, tem-se o Conselho Nacional de Secretários Municipais de Saúde (CONASEMS) e para os estados, temse o Conselho Nacional de Secretários Estaduais de Saúde (CONASS).
} 
Em 1996 surgiu a Norma Operacional Básica de 1996 (NOB 96) a qual trazia a não ocorrência de retrocesso no processo de descentralização, diminuição da burocracia do processo sem enfraquecer os requisitos para assumir novas funções, oferecimento de mais vantagens e autonomia às formas de gestão menos complexas, como os municípios. A NOB 96 teve como finalidade promover e consolidar o pleno exercício, por parte do poder público municipal e do Distrito Federal, da função de gestor da atenção à saúde dos seus munícipes, com a consequente redefinição das responsabilidades dos Estados, do Distrito Federal e da União, avançando na consolidação dos princípios do SUS. Houve ênfase ao planejamento da atenção básica, médica e alta complexidade, havendo maior repartição de funções, responsabilidades, requisitos e prerrogativas. A NOB/96 trata também do financiamento e da destinação de recursos aos Estados e Municípios.

Vê-se, de modo amplo, que as NOB tiveram papel relevante não só para regulação da saúde, mas se configuraram como instrumentos definidores do modelo de atenção à saúde e direcionadores de políticas públicas para o setor saúde.

Afirma-se também que a descentralização se desenvolveu com mais intensidade em um conjunto de estados e municípios dotados de estruturas, recursos e capacidade gerencial acima da média do país, fazendo com que a expansão da autonomia ocorresse primeiro em um pequeno grupo de municípios de maior porte, em geral capitais de estados, para depois contemplar um conjunto mais amplo de municípios.

Na década de 90 vivenciaram-se crises econômicas, contenção de gastos públicos. Por outro lado, a prevalência da municipalização, aumentou a fragmentação das ações e serviços de saúde e dificultam a realização do princípio da integralidade do SUS. Além disso, Guerra (2015) cita como vetores que interferem diretamente na capacidade de assumir as responsabilidades impostas pelo SUS, a diversidade do perfil dos municípios, o grande número de municípios pequenos, sendo alguns deles sem condições institucionais de viabilidade.

Em janeiro de 2001, surge a Norma Operacional de Assistência à Saúde -NOAS/SUS, tendo em vista a necessidade de dar continuidade ao processo de descentralização e organização do Sistema Único de Saúde, a partir, por exemplo, de uma maior articulação entre as Secretarias Municipais e Estaduais de Saúde visando organizar o processo de regionalização, promovendo o acesso da população às ações e serviços de saúde, de acordo com as necessidades de cada região.

A norma dispõe que para o aprofundamento do processo de descentralização, deve-se ampliar a ênfase na regionalização e no aumento da equidade, buscando a organização de sistemas de saúde funcionais com todos os níveis de atenção, não necessariamente confinados aos territórios municipais.

A NOAS 2001 tem como atribuições explanar quais são e como são financiados e divididos no território brasileiro os serviços de média e alta complexidade do SUS além de explicitar as responsabilidades, os requisitos relativos às modalidades de gestão e as prerrogativas dos gestores municipais e estaduais.

\subsection{O Pacto pela Saúde e o Pacto de Gestão como instrumento necessário para a busca de consolidação do SUS}

Em 2006, os gestores do SUS regulamentaram por meio da Portaria $n^{\circ}$ 399/GM, a divulgação do Pacto pela Saúde 2006, com base nos princípios constitucionais do SUS e ênfase nas necessidades de saúde da população, implicando na aprovação de três diretrizes, quais sejam: 1) Pacto pela Vida: seria um conjunto de compromissos sanitários derivados da análise de saúde do país, assim como do estabelecimento de prioridades pela União, estados, municípios; 2) Pacto em Defesa do SUS: envolve ações concretas e articuladas pelas três instâncias federativas no sentido de reforçar o SUS como política de Estado mais do que política de governo e de defender, os princípios basilares dessa política pública, trata-la como um direito, inscrito na Constituição

Revista de Direito Brasileira | Florianópolis, SC | v. 28 | n. 11 | p.104-116 | Jan./Abr. 2021 
Federal; 3) Pacto de Gestão: estabelece as responsabilidades de cada ente federado de forma a tornar mais claro quem deve fazer o quê, contribuindo para o fortalecimento da gestão compartilhada e solidária do SUS, nos aspectos da descentralização; regionalização; financiamento; planejamento; Programação Pactuada e Integrada - PPI; regulação; participação social e gestão do trabalho e da educação na saúde.

O Pacto de Gestão do SUS, representa a normatização operacional do Pacto pela Saúde, função que até então era exercida pela NOB 01/96 e pela NOAS 01/02. Com ele, foram estabelecidas as responsabilidades que cada esfera de governo possuiria na operacionalização do citado Pacto de 2006, estabelecendo-se um sistema de repartição infra legal de competências sanitárias.

A partir da normatização dos mencionados Pactos, com destaque para o Pacto de Gestão, a responsabilização dos gestores das três esferas federativas passou a ser tratada com maior importância, visto que se passou a estabelecer metas a serem atingidas de forma cooperativa e solidária entre os entes e compromissos passaram a ser previamente negociados.

\subsection{Demais regulamentações para implementação do Sistema Único de Saúde}

Em 2008, o Ministério da Saúde instituiu a Política Nacional de Regulação do SUS por meio da Portaria n ${ }^{\circ} 1.559$ de 2008 implantada como instrumento que possibilitou a plenitude das responsabilidades sanitárias assumidas pelas esferas de governo. A Política Nacional de Regulação foi organizada em três dimensões: Regulação de Sistemas de Saúde, efetivada pelos atos de regulamentação, controle e avaliação de sistemas de saúde; Regulação da Atenção à Saúde, efetivada pela contratação de serviços de saúde, controle e avaliação de serviços e da produção assistencial, regulação do acesso à assistência e auditoria assistencial e Regulação do Acesso, efetivada pela disponibilização da alternativa assistencial mais adequada à necessidade do cidadão por meio de atendimentos às urgências, consultas, leitos e outros que se fizerem necessários.

Em 2011, é publicado o Decreto no 7508, que Regulamenta a Lei $\mathrm{n}^{\mathrm{o}} 8.080$, de 19 de setembro de 1990, para dispor sobre a organização do Sistema Único de Saúde - SUS, o planejamento da saúde, a assistência à saúde e a articulação interfederativa. O Decreto 7508/2011 definiria as responsabilidades individuais e solidárias dos entes federativos com relação às ações e serviços de saúde, os indicadores e as metas de saúde, os critérios de avaliação de desempenho, os recursos financeiros que serão disponibilizados, a forma de controle e fiscalização da sua execução e demais elementos necessários à implementação integrada das ações e serviços de saúde.

No ano 2000, foi aprovada a Emenda Constitucional n ${ }^{\circ} 29$, que promoveu a vinculação de recursos para a saúde nos orçamentos das três esferas de governo, assegurando um patamar mínimo de recursos $^{3}$ da União, estados e municípios. Estados e municípios foram obrigados a alocar.

Tostes (2007) afirma que sobre o financiamento do SUS ficou decidido que ele seria feito de duas formas: com recursos do orçamento da seguridade social (receitas contributivas) e outra com os orçamentos da União, dos Estados, do Distrito Federal e dos Municípios. Assim, orçamento da seguridade social era responsável pelo financiamento tanto da saúde quanto das áreas da previdência social e da assistência social.

Em 2005 houve a aprovação, pela Comissão de Constituição e Justiça da Câmara dos Deputados, do projeto de lei complementar que define os gastos públicos em saúde. A regulamentação desta veio auxiliar a emenda constitucional $\mathrm{n}^{\circ} 29$, de 2000 , que estabelece a obrigatoriedade dos gastos em serviços de saúde vinculados à arrecadação de Estados e municípios, que veio a ser publicada na forma da Lei Complementar $n^{\circ} 141 / 2012$, regulamentando o $\$ 3^{\circ}$ do

\footnotetext{
${ }^{3}$ De acordo com o disposto na EC 29/2000, à época de sua criação, pelo menos 7\% das receitas resultantes de impostos e transferências constitucionais eram destinados à saúde. Em 2001 até 2004, esse valor foi ampliado, alcançando o patamar mínimo de $12 \%$ para os Estados e $15 \%$ para os municípios.
} 
artigo 198 da Constituição Federal de 1988, fixando os valores mínimos a serem aplicados anualmente pela União, Estados-membros, Distrito Federal e Municípios em ações e serviços públicos de saúde, além de estabelecer critérios de rateio dos recursos de transferências para a saúde, assim como as normas de fiscalização, avaliação e controle das despesas com saúde nas três esferas de governo.

Em 2016, foi aprovada a EC 95/2016 a qual foi incorporada ao ordenamento jurídico sob o argumento de que em breve o Brasil sofreria um colapso econômico, em especial em setores como a Previdência Social (que integra o conceito de Seguridade Social composto ainda pela Saúde e pela Assistência Social). Acontece que é evidente a ocorrência de retrocesso no financiamento do sistema único de saúde brasileiro, que passa a partir de 2018, a ser calculado conforme o valor do limite referente ao exercício imediatamente anterior, corrigido pela variação do Índice Nacional de Preços ao Consumidor Amplo - IPCA, publicado pelo Instituto Brasileiro de Geografia e Estatística, ou de outro índice que vier a substituí-lo, para o período de doze meses encerrado em junho do exercício anterior a que se refere a lei orçamentária.

Segundo a ANFIP, o argumento de que a Seguridade está à beira de um colapso sem medidas - com a Emenda do Ajuste Fiscal- não representa a fiel realidade dos fatos. Vejamos:

Mesmo com renúncias fiscais, queda na economia e no emprego, o resultado foi superavitário em 2015, assim como nos anos anteriores. Para amparar o discurso do deficit, o governo desconsidera dezenas de bilhões de reais das receitas de contribuições sociais e ainda acresce outros bilhões de reais em despesas que não poderiam entrar nessas contas. (...) (ANFIP, 2018).

Além de limitadora, retrocedente, a EC 95/2016 ainda se baseia em dados contábeis de déficit orçamentário da seguridade que podem ser rebatidos ao discriminar as contas de receitas e despesas que o Estado apresenta.

Pode ainda ser elencado que a EC 95/2016, no período da sua criação, não levou em conta que a população projetada para 2036 é de 226,9 milhões de habitantes, 10,1\% superior à de 2016. As projeções do IBGE referentes à população brasileira com 60 anos ou mais, que hoje representa cerca de $12,1 \%$ do total, em 2036 representará $21,5 \%$, ou seja, representará quase o dobro da atual (+ de 96\%), e a população com 80 anos ou mais aumentará em mais de $150 \%$, passando de 3,5 milhões para 8,8 milhões, o que, evidentemente, pressionará o gasto público com saúde.

Todas essas legislações que tratam sobre o financiamento do SUS buscam assegurar que o sistema de saúde público brasileiro obtenha os recursos mínimos necessários à operacionalização das ações em saúde no âmbito do SUS. No entanto, dificilmente resolverá os problemas do financiamento do sistema de saúde público brasileiro, visto que cabe ao gestor público decidir como os recursos devem ser aplicados. Para a concretização do SUS, além de gestão, necessário se faz busca por um equilíbrio federativo, em que haja de fato descentralização administrativa.

\section{CONSIDERAÇÕES FINAIS}

Constata-se com a presente pesquisa que existem problemas estruturais e uma regressão da legislação pátria quando trata do tema direito à saúde. Há ainda a problemática da complexidade do sistema de repartição de receitas, com a maior parte dos recursos municipais de saúde sendo provenientes da União e o enxugamento de valores dispendidos a garantia dos direitos sociais, após a EC 96/2018.

Para construir o pensamento formulado e tratar sobre a existência de centralização da União, foram apresentados conceitos de saúde trabalhados por Rawls (2008) que a conceitua como um bem protegido e tutelado pelo direito em âmbito internacional, sendo considerado primário; por Sem (2000), aborda a saúde como uma condição para o desenvolvimento e Daniels (1985) que compreende a saúde como um elemento indispensável para a teoria da justiça, que busca a

Revista de Direito Brasileira | Florianópolis, SC | v. 28 | n. 11 | p.104-116 | Jan./Abr. 2021 
igualdade de oportunidades e pode ser considerada um problema de justiça distributiva, que envolve resultado e causa das desigualdades sociais.

Buscou-se apresentar largamente o histórico do direito à saúde brasileiro após a promulgação da Constituição de 1988 e leis específicas que trataram sobre a instituição e regulamentação do Sistema Único de Saúde.

Sobre o tema, é importante mencionar que por muito tempo, a saúde no Brasil estava mais voltada a atender as pessoas que contribuíam, que possuíam vínculos empregatícios. Aos considerados pobres e indigentes, o atendimento era precário, realizado pelas Santas Casas, que vivia em superlotação.

A partir de meados dos anos 70, ocorreu a Reforma Sanitária. Foi a partir desse momento, em meio a grandes transformações - incluídas tecnológicas, de organização, divisão de trabalho, de ideologia, condições políticas e econômicas em que se visava a superioridade do livre mercado - que foi pensado em um dos mais avançados sistema de saúde do mundo, que possui como características, a universalidade, a integralidade.

Ainda assim, conforme traz Campos (2007) o Sistema Único de Saúde é considerado uma reforma social incompleta, com implantação heterogênea, desigual, conforme características geopolíticas ou geoculturais de cada região, com problemas de insuficiência de recursos, de estruturação, de funcionamento.

O desafio para a manutenção de um Sistema Único de Saúde mesmo diante das limitações e problemáticas envolvendo a repartição de recursos e competências entre os entes, tem sido garantir a ampliação das responsabilidades dos municípios na atenção básica, estabelecendo ainda o processo de regionalização como estratégia de hierarquização dos serviços de saúde e de busca de maior equidade, conforme pensado por Daniels (1985) tomando por fulcro a Teoria de Justiça apresentada por Rawls, além disso, insta destacar a necessidade de criação de mecanismos para fortalecer a gestão do SUS e proceder à sua efetivação.

\section{REFERÊNCIAS}

ANFIP. Associação Nacional dos Auditores Fiscais da Receita Federal do Brasil e Fundação ANFIP de Estudos da Seguridade Social e Tributário. Análise da Seguridade Social 2015. 16 ed. Agosto de 2016. Disponível em:

http://www.anfip.org.br/doc/publicacoes/20161013104353_Analise-da-Seguridade-Social 2015_13-10-2016_Anlise-Seguridade-2015.pdf. Acesso em: 03 de jan. 2018.

SILVA, José Afonso da. Curso de Direito Constitucional Positivo. São Paulo: Malheiros, 2001.

ALMEIDA, Célia. Reforma de sistemas de saúde: tendências internacionais, modelos e resultados. In: GIOVANELLA, Lígia; et.al. Políticas e Sistema de Saúde no Brasil. 2. ed. rev. e amp. Rio de Janeiro: FIOCRUZ, 2012.

BATISTA, Paulo Nogueira. O Consenso de Washington: a visão neoliberal dos problemas latinoamericanos, 1994.

BONAVIDES, Paulo. A Constituição aberta: Temas políticos e constitucionais da atualidade, com ênfase no Federalismo das Regiões. 3 ed. São Paulo: Malheiros, 2004.

BRICEÑO-LEÓN, Roberto. Bienestar, salud pública y cambio social. In: Salud y equidad: uma mirada desde las ciências sociales. Rio de Janeiro: Editora FIOCRUZ, 2000. 
CAMPOS, Gastão Wagner de Sousa. Reforma política e sanitária: a sustentabilidade do SUS em questão? Revista Ciência e Saúde Coletiva, v. 12, n. 2, p. 301-306, 2007.

CARVALHO, Gilson. A saúde pública no Brasil. Revista de Estudos Avançados, v. 27, n. 78, 2013.

COHN, Amélia; ELIAS, Paulo E. Saúde no Brasil: políticas e organização de serviços. 4 ed. São Paulo: Cortez: CEDEC, 2001.

DALLARI, Sueli. Os estados brasileiros e o direito à saúde. São Paulo: Hucitec, 1995.

DANIELS, N. Just health care: studies in philosophy and health policy. Cambridge, London: Cambridge University Press, 1985.

DINIZ, Isadora Moraes; RAMOS, Edith Maria Barbosa. Direito à saúde e judicialização: uma análise da atuação do Conselho Nacional de Saúde no aprimoramento da prestação judicial nas demandas de saúde. Dissertação (Mestrado) - Programa da Pós - Graduação em Direito. Universidade Federal do Maranhão: São Luís, 2015.

DOURADO, Daniel de Araújo; ELIAS, Paulo Eduardo Mangeon. Regionalização e dinâmica política do federalismo sanitário brasileiro. Revista Saúde Pública, São Paulo, v. 45, n. 01, 2010, p. 204-211.

DWORKIN, Ronald. A virtude soberana: a teoria e a prática da igualdade. 2 ed. São Paulo: Editora WMF Martins Fontes, 2011.

ELIAS, Paulo Eduardo Mangeon; DOURADO, Daniel de Araújo. Sistema de saúde e SUS: saúde como política social e sua trajetória. In: IBAÑEZ, Nelson; et. al. (Orgs). Política e Gestão Pública em Saúde. São Paulo: Hucitec Editora: Cealag, 2011.

ESCOREL, Sarah. Reviravolta na Saúde: origem e articulação do movimento sanitário. Rio de Janeiro: Editora Fiocruz, 1999.

GUERRA, Daniele Marie. Descentralização e regionalização da assistência à saúde no estado de São Paulo: Uma análise do índice de dependência. 2015. 209 f. Tese (Doutorado em Saúde Pública). Universidade de São Paulo, São Paulo/SP, 2015. Disponível em: < http://www.teses.usp.br/teses/disponiveis/6/6135/tde-16112015-112549/pt-br.php>. Acesso em: 02 de jun. 2017.

LOUREIRO, João Carlos. Direito à (proteção da) saúde. In: Revista da Defensoria Pública. Edição Especial Temática sobre Direito à saúde, ano 01, n. 01, jul./dez. 2008.

LUZ, Madel Therezinha. Saúde: origens etimológicas do termo. In: Dicionário de Educação Profissional em Saúde, 2009. Disponível em: <http://www.sites.epsjv.fiocruz.br/dicion ario/verbetes/sau.html>. Acesso em: 20 de jul. 2017. 
PRADO, Ana Paula Barroso de Salles Paiva. Direito fundamental à saúde: direito social tratado como direito individual no Brasil. Dissertação (Mestrado Em Direito). Faculdade de Direito do Sul de Minas, Porto Alegre, Minas Gerais, 2012.

RAMOS, Edith Maria Barbosa. Universalidade do Direito à Saúde. EDUFMA: São Luís, 2014.

RAWLS, John. Uma teoria da justiça. Brasília, DF: Unb, 2008.

RAWLS, John. Justiça como equidade: uma reformulação. Tradução Claudia Berliner. São Paulo: Martins fontes, 2003.

RESSINGER, Simone. Aspectos controvertidos do direito à saúde na Constituição brasileira de 1988. Dissertação. (Mestrado em Direito). Pontifícia Universidade Católica de Minas Gerais, Belo Horizonte, 2008.

SARLET, Ingo Wolfgang. Dignidade da Pessoa Humana e Direitos Fundamentais na Constituição Federal de 1988. Porto Alegre: Livraria do Advogado, 2007.

SCLIAR, Moacyr. História do conceito de saúde. Pysis: Revista Saúde Coletiva, Rio de Janeiro, n. 17, v. 01, p. 29-41, 2007.

SEN, Amartya. Desenvolvimento como liberdade. São Paulo: Companhia das Letras, 2000.

SILVA, Juliana Gomes da. Orçamento Público em saúde: uma análise da EC 29/2000 nos estados brasileiros. Monografia. (Gestão de Políticas Públicas). Universidade de São Paulo, 2011. Disponível em: <http://www.each.usp.br/flamori/images/TCC_Julia na_2011.pdf> Acesso em: 10 de ago. 2017.

TANAKA, Oswaldo Yoshimi; SCATENA, João Henrique Gurtier. Os instrumentos normalizadores (NOB) no processo de descentralização da saúde. Revista Saúde e Sociedade, n. 10, v. 02, p. 47-74, 2001. Disponível em: < http://www.scielo.br/pdf/sausoc/v10n2/05.pdf>. Acesso em: 10 de out. 2017.

TOSTES, Monica Curcio de Souza. Pacto Federativo e a Política Sanitária municipal brasileira: os casos do Rio de Janeiro e de Niterói pós 90. Dissertação (Mestrado em Ciência Política). Universidade Federal Fluminense, Niterói, 2007. 